\title{
HAVE STILL THE ADULTS A GENUINE NEED FOR LEARNING?
}

\author{
Rodica Mariana NICULESCU PhD, \\ University Transilvania of Brasov \\ rodicanic@unitbv.ro \\ rodica_niculescu@yahoo.co.uk
}

\begin{abstract}
The paper intends to highlight an important issue: the specifics of adults' learning process nowadays, the dynamics of motivation for formal learning activities (within tertiary education and/ or lifelong learning), the difficulties of educators in relation to adults' learners, and the position of society versus this segment of permanent education. Based on a systematic observation along five academic years, it is stressed that, the stated conclusions are required to be verified by an in depth research.

The paper announces the existence of such a research, whose results will be the topic of further papers. Some core aspects of this approach are presented. The paper has the explicit intention to emphasize a thorny contemporary problem, by pointing out some worrying aspects in adult education, which may have earlier roots in ontogenesis. The presentation intends to be an additional and serious pleading for considering education a genuine national and universal priority, by renouncing to the pretend this priority only in the official papers. The worsening of the presented aspects, within the conditions of a nebulous actuality is highlighted and, also the huge danger of the "time of to pretend" (meaning to mime a reality that does not exist as such) is explained.
\end{abstract}

Key words: adult education, adults' learning process in actual time, effects of to pretend as a banner of nowadays life.

\section{The world we live in}

The issue of adaptation has become a real problem for the society we live in, because it has brought many changes in adults' life, with a remarkable rate and speed of these changes. The entire Earth has turned the borders of its sequences into delicate traces and has facilitated the flight from one end to the other not only with the speed of airplanes of the latest technology, but with rapidly communicated words and thoughts, as well. 
In only twenty-five years, traditional distinctions between generations have widened, with antagonisms taking increasingly nuanced forms, with tension and apparent risks of incongruity. This happens despite the tendency to preserve appearances to a greater extent than ever. To pretend (meaning to mime a reality that does not exist as such), as a generalized attitude, seems to have become an accepted motto with open arms more or less wide, but with an obvious tendency to become permanence. How the people cope with all these is an issue of learning. The need of learning receives deep and complex meanings nowadays. Unfortunately, these meanings do not imply always positive facets.

\section{Learning process and aspects of learning, nowadays}

The learning process is a very natural one, for all beings in this world. However it has specific features for human beings. In this particular case, the learning process involves the acquiring of knowledge, as cognitive basics of competencies, the development of appropriate capacities (skills), necessary to an effective adaptation to permanent and speedy changing, all accompanied by efficient development or modeling of attitudes and appropriate behaviors as answers of more and more complex tasks.

Psychologists and specialists in education have scrutinized and analyzed in depth the peculiar aspects of the learning process. A consistent number of learning theories are to be found in literature. These theories are seen as" a body of principles advocated by psychologists and educators to explain how people acquire skills, knowledge, and attitudes. (The learning process, 2003). Theories of learning may be genuinely important for designing an effective educational process based on appropriate teaching and assessment methodologies, both focused on learning, precisely because they try to explain how people learn. The role of the motivation for learning, the core characteristics of the learning process, different learning styles etc. are other connected issues of the mentioned theories.

\subsection{Characteristics of the human learning process}

Generally speaking, there are some core ideas emerging from an extremely different approach of the complex process of human learning. They are mainly focused on the characteristics of the learning process. Thus, some of the commonly recognized features can be synthesized in several points.

\section{$>$ The learning process of a human being always has a purpose.}

For the other beings, the purpose of an action does not genuinly exists; it is more correct to speak about the existence of a triggering cause. Basicly, 
they try to find food, security, development, and to ensure the species perpetuation.

Any being must learn in a particular way how to meet specific needs. The pyramid of necessities is much more complex for human beings. It is interesting to notice that the genuineness of the purposes of learning is considerably distorted at human beings comparatively to any other beings on the Earth, in spite or, maybe, because of this complexity.

The specificity of the range of the adults' learning targets in this decade of the third millennium is one of the hypostases of the previously mentioned issue.

The learning purpose may be significantly different, from a learner to another, even if they are involved in the same or similar learning activities. (Bakar, K. A., Sulaiman, N. F. \& Rafaai, Z. A. M. , 2010). The purpose can be designed for a long, medium or short term, and the action of learning is triggered by a very personal motivation (intrinsic or extrinsic, as well, depending on the place of the established target; it can be placed inside or outside of the learning process itself). The literature stresses that there are differences of performance according the age and depending on the type of received feedback. (Simon, J. R., Howard, J. H., \& Howard, D. V. 2010)

Based on a long term process of managed direct observation, one can say that a lot of peculiar and differential aspects are obvious at the adults of nowadays who are involved in different types of formal learning process: master degree programs, adult's postgraduate training courses or, even simply training sessions for adults, without professional formal implications. Thus, no matter to what type of activity they are involved in, the observed adult subjects have seemed to have a less and less genuine interest for the learning process itself. In other words, the adults of nowadays appear as being less and less interested in the essence of the learning process: to acquire valuable and effective competencies (both for general usage and for professional or social fields of applicability).

Their enrolment in programs that assume learning process is, rather, determined by the social needs (as need for affiliation); more specifically, nowadays one can speak about the social need of belonging to certain social categories, the most often to those defined by the possession of diplomas that attest the completion of some studies. Sometimes, much enough, and more often, apparently, the purpose is not even that previously presented. A kind of spirit of imitation, of flock effect is the roots of the agglomeration at enrollment for defined specialties that are changed from time to time, as the fashion is changed. This is a typical situation not only for the master degree programs, but for undergraduate ones as well; the situation also appears to be similar when it is about the advertised training programs for adults. In this particular case the fashion appears to be the main trigger of the enrolment. 
The necessary credits for different professional or social purposes may also be the enrolment trigger. The saddest aspect is that a minimum quantum of curiosity does not exist beyond the mentioned enrolment based to be in fashion or to obtain the so hunted credits. This shade of curiosity could be used as a starting point by the trainer for an effective learning process.

But it seems that a kind of a a double-sense contagious influence is engulfed by a kind of swirl: students with no purpose for genuine learning, with an absent or low interest for acquired learning experiences determine absent or low level of concern for designing and implementing learning situations on the trainers side.

The effectiveness of the learning activities is under the shadow. The interest in the show, to create advertising effects, seems to be the basic concerns of many bidders for adult learning activities. In this case, for the adults' training designers consider obsolete, useless to create appropriate assessment tools for an adequate evaluation focused on the effectiveness of learning. Two aims seem to be necessarily covered by the organizers side: to tick officially or formally requested activities and/ or earning money if the training courses are to be paid. For beneficiaries it become important to earn points for portofolio, credits, or, pure and simple to be in fashion. Thus, "to pretend behavior" becomes a master in this field.

\section{The learning process has a significant numbers of facets.}

These facets (The learning process, 2003) leaded the theorist to classify learning on different types focused on:

- the canals of learning (perceptual, motor, verbal, conceptual, problem solving, and emotional);

- the field of activity were the learning process occurs or is meant for; in this case the use and the development of specific capacities are involved; it is about:

○ intellectual skills/ competencies, as facilitators of performance of a culturally or professionally relevant task;

- cognitive strategiesas ways/ strategies for learning in order to develop the mentioned intellectual capacities, in a more effective way. They refer to how to organized the learning steps, to predict or guess meanings from the context, to summarize meanings, to use memory and imagination as supports in learning approach, how and how much to repeat what is to be learned, attitudinal adjustments or changes in order to increase the effectiveness of the learning process.

- Others two facets of the learning process are connected to the deepness of learning: surface or deep learning.

The multiple faces and the complexity of learning process are also intimately influenced by what the specialists in education name as hidden curriculum. The learning process may be explicitly focused on something 
specific, but the context, the way of teaching, the selection of the learning situation and personality of teacher, the personalities of the learners and their interconnections have significant effects upon what and how the students learn and on the quality of the learning process outcomes ( adapted after The learning process, 2003)

The issue of this hidden curriculum gives a plus of complexity to the learning process, in the light of what the previous considerations about the learning purposes of students, with their effects upon the quality of the delivered learning activities have implied. Two fields of disinterest seem to intertwine and, consequently, to influence each other under the sign of claiming to do something of quality. This unfortunate interpenetration, in which the facets of learning are used rather as design statements (long lists of competencies to be achieved) or as tools in the stage performance of the show (the facets: perceptual, motor, verbal, conceptual, pretending problem solving, and much emotional, being intensely used); these lead towards the already explained as "the land of to pretend". And, what it is interesting is that as larger the pretending land is as more the further presented characteristic of the learning process becomes, unfortunately, less a necessity as it should be, but only as an appearance.

\section{> Genuine learning must be an active process.}

This feature should be extremely important for a learning activity designer. The designer has to be aware that the learning activity involves learning situations suitable for a specific group of learners and derived from the necessity to achieve specified and previously defined finalities (outcomes, expectations for learning). The designer must genuinely understand the process of developing competencies. This process is based on the correct considering of the structure of competency: the necessary knowledge base, the connected capacities developed by practicing, and directing and supporting attitudes. It is obvious that the action of the students/ learners is essential for obtaining better results for all the three components of competency and for the competency itself as a synergetic result of their interconnection. When it is about the discovered knowledge the active implication of learners leads to better achievement, of course. If they act aware about a specified purpose, aiming to fulfill defined outcomes both capacities and attitudes are properly developed. Thus, acting by learner is a core condition of the learning process quality. The simple possession of knowledge without the capacity, the desire and motivation to apply them in adequate contexts to solve real problems (professional, social, or even creative cognitive) is a false end useless result. 


\section{$>\quad$ Learning is the result of the experience}

The turning of the learning situations designed by educator or put into action by the life itself into learning experiences unique for each learner is a core issue of curriculum theory. The importance of the awareness of the purpose of learning for both educators and learners (within formal, nonformal and even informal education where the learner is the only selector of the learning situations offered by life) should not be demonstrated.

But, even if these ideas are, for a long time, genuine truisms, the reality of the education and training seems to not consider them other than declarative. The so called activism in learning has more and more the essence of acting within a surrogate active process of learning, where the students move a lot, speak together, act etc. But it is not valued a really concerted context, with genuine concern about what is being acquired and at what level of quality. The care for fun, to feel good becomes prevalent. Of course, this positive emotional context should not be neglected, but when it becomes an end in itself, the effects are rather negative. The quality of the each stage of acquired experiences becomes the starting point for what kind of learning experiences are asked and enjoyed on further stages. The pretending attitude, both from educators as designer and managers of the learning process, and learners as beneficiary of it, may be (and it is actually) one of the sources for the superficial attitude (previously described) of those who learn in this final of the first decade of the third millennium.

\subsection{Learning process seems to be governed by principles}

These principles are generally accepted, even if their order or formulations are slightly different.

\section{$>$ Learning process has a motif- principle of readiness}

Individuals learn sensible better when they have an obvious motif of learning. The role of the educator or the trainer in developing this awareness is determined by the learners' age and by their level of instruction and culture. This motivation for a specific learning activity is sensible influenced by the hierarchy of all the other activities in the learner concrete life with their specific motivation. Prioritizing is itself a competence that has to be learned along the educational process, especially inside the schooling period. The motif of learning can emerge from inside the learning process or from outside of it. Children learn first because they need to be loved by their parents, by the teacher, or, if the stimulation from outside is an inappropriate one, they learn for different kind of recompenses. Normally, the motivation for learning follows a route from outside to inside the learning process if this is professionally leaded by the educators. There are a lot of areas where the learning process remain extrinsically motivated, and it is normal to be like this. But there is a real danger when nothing is learned by a teenager or, later, 
by an adult, with a genuine intrinsic motivation. (Simon, J. R., Howard, J. H., \& Howard, D. V., 2010); Oletić A., Ilić N., 2014); Chiew Fen Ng and Poh Kiat Ng, 2015).

The situation appears more complex for adults' learning. Generally speaking they have, simultaneously, several statuses (as professionals, parents, son/daughter, sister/brother, colleague etc). Each of these statuses arise requests for learning as a general process and sometimes as an activity within a formal context. When an adult become enrolled in a formal training activity (within a professional field for further training and updating, or for re-training in another professional field etc.) at the beginning both the extrinsic and intrinsic motivation could appear: it depends on context and is different from person to person. The trainer may and should have a huge role for ensuring an internalization route of the trainee's learning motivation.

However, the trainer's effort is not enough. The trainee comes with his/her own purpose of the enrolment in the formal learning activity. The effort of the trainers, sometimes, does not lead to expected results, when this enrolment is rooted on the spirit of the herd, the trends of the fashion for training at a given moment, or it occurs as a compulsory act, force by an authority or an important need for professional ascension more than a genuine wish for professional development.

There are no supportive learning experiences in the history of such kind of learners to be used as fundamentals. They are not ready to learn. In this case, the delicate issue of how the trainers themselves are motivated by their trainees becomes a serious aspect.

\section{$>$ The principle of effect}

- This principle is strongly connected to the previously mentioned one. The importance of the emotional reaction of the student along and at the end of the learning process is highlighted. The positive and appropriate strong emotions have obviously a supportive influence for the learning experiences. This principle is extraordinary important with a condition: positive emotions should not be a purpose in themselves: they should accompany the learning process. A properly supportive role is determined by a moderate intensity; the positive emotions should be prevalent in correlation with the incidentally negative emotions that could produce frustration, confusion or futility for learner, but that cannot entirely be avoided (adapted after: Simon, J. R., Howard, J. H., \& Howard, D. V., 2010, and The learning process. 2003).

\section{$>$ The principle of intensity}

On its turn, the principle of effect is connected to the principle of intensity. An exciting learning situation teaches more than a routine or boring one. An intense activity has significant effects on the quality of the 
students' learning experiences. The activism of learning is also involved here because it is obvious that something that students have acted, experienced, and practiced (for repetition purposes, with consolidating effects), the aware reorganizing of knowledge and capacities lead to outcomes generating positive and supportive emotion.

$>$ The principles of recency and primacy (The Learning process. 2003$)^{13}$

The recency principle states, that things most recently learned are best remembered. However, this principle should be understood in a complex way. The learning process must have continuity, fluidity, consistency, and flexibility. These attributes are difficult to be achieved in adults' training for several reasons. Their own history as learners is different for an adult to another. They have significantly different initial competencies (general-cognitive, specialized, etc), a wide spectrum of motivation for learning, personal attitudes versus their enrollment in the training program, and, not at all to be neglected, they have nuanced features of personality.

Thus, to answer properly about an old knowledge or to be able to activate an old capacity could be a success for some of them, for others may be a failure. The mastery of the trainer to design learning situations taking into account all the possible differences and permanently adjusting the design to the necessity of each moment of the implementation are conditions for ensuring the previously mentioned characteristics of the learning process. Sometimes, the correction of bad or inaccurate acquired knowledge and/or capacities, the influence upon inappropriate attitudes must be a core concern of the trainer and these are sources of difficulties because the principle of primacy is not facilitated. This principle states that knowledge or a capacity must be correctly learn for the very beginning, for being further the bases for development. The process of correction appears to be much more difficult that the adequate learning from the very beginning.

The above presentation highlights several points of attention. They are implied by the figure $n r .1$

A formal learning process involves two human categories: the provider of the learning situations (WHO) and the learner (for WHOM) the beneficiary of the learning situation, the learner. The learners may involve themselves in the learning process in two ways: highly aware and with a clear learning purpose and using the learning situation as a learning

\footnotetext{
${ }^{13}$ The learning process, 2003, http://www.dynamicflight.com/avcfibook/learning_process/
} 
opportunity, or as simple actors (more or less passive) of it. Both cases are followed by a unique learning experience for each learner. Nevertheless, the quality of the learners' acquisitions is different for each of them, according to the degree of the awareness, voluntarily implied effort, and effective involvement in the learning process.

The two main actors of the learning process (educator and learner) have well defined roles: the educator/ trainer is the author of designing and managing the whole process of learning through his/her manner of teaching. The learner is the beneficiary, the actor and manager of his/her own process of learning.

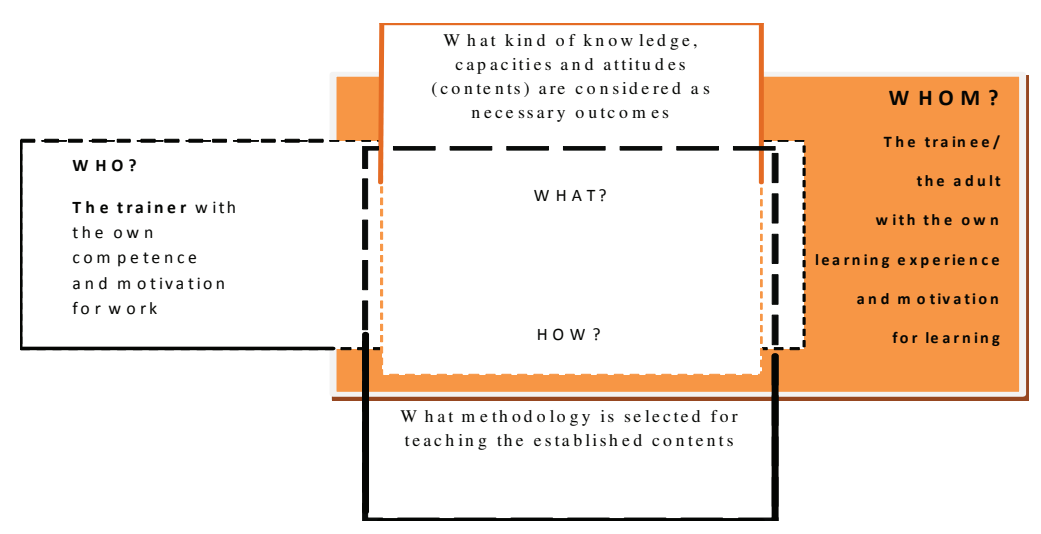

Figure 1: The learning process and its elements

The results of the learning process are designed as expected outcome on the learner's level. Simultaneously, the trainer gets his or her own learning experience after implementing and assessing the learning situation design. The trainer learns more about the trainees' psychology, about the influence of their personal learning style on the learning outcomes. In the same time the trainer learns about the appropriateness of the contents and of the selection of the teaching methodology, about the effectiveness of the teaching style. The trainer may also obtain valuable information about the human relations implied by a learning situation implementation (strengths, weaknesses, opportunities, and threats). The only condition for all this aspects of a trainer's learning experience is a genuine reflective attitude based on a strong motivation for teaching.

Thus, the two main actors of the learning process influence each other in a very interesting way. The teaching style interconnects with the learners' learning styles. Their interconnection generates important information for the designs of future learning situations (selection and the maintenance of the contents, communication ways, and, especially the methodology of teaching- 
learning-assessing process). An over- motivation and a great effort of the trainer to provide qualitative training sessions impacted by the lack of motivation of the learners, their resistance to an in depth approach, for practicing, generate frustration.

Usually, these feelings terns into two possible direction of a further action of the trainer:

- the trainer tries to find out those elements that are desirable for a specific group of trainees and fructifying them for at least a minimum quality of the results of the learning activity.

- he or she lets things go on no matter what happens, because of a too obvious indifference from the trainees side. The choice is strongly determined by institutional, social and economic reasons.

Sometimes, and lately, maybe too more often, the attitude of "pretending to do what is requested" seems to be the winner, and in this situation the quality of work remains only a "big nothing nicely painted".

\section{Perverse effects of the confusion between the genuine need for learning and other specific needs of adults}

The previous presentation highlighted the difficulty of working with adults in the training area.

Some key ideas about adults' learning and their specific need of learning in the new millennium should be stressed. Generally speaking the adults have a complex manner of learning. Their individual learning style, progressively developed along ontogenesis process is one facet of difference between adults when they become formal learners: this facet is strongly influenced by their perception of self, their complexes and their self-esteem.

Usually a group of trainees is extremely heterogeneous: they may have the same initial type of training, the same specialty sometimes, but they however have their own professional experience, the personal status of each one, their own interpersonal relations. All these are individually connected to each learner's perception of the trainers, of the learning activity itself; and all these create a complex of influences (hidden curriculum) with interesting and often perverse effects on the learning outcomes.

Our contemporary life appears to have some characteristics as interesting sources for the difficulty to work efficiently with the young or less young adults.

One important cause may be the superficiality of thinking about the genuine utility of learning, accompanied by the crazy run for the acquisition of diplomas or other forms of certification, to get points all only for having a thick personal portfolio.

Another possible cause may be the lack of interest for reading, the tendency of compressing and impoverish the verbal language, because of the 
virtual communication, completed with the obvious attitude of avoiding an in-depth information and almost the runaway behavior from thinking with their own mind, after a so long lack of practicing this.

The academic work with young adults and adults in their middle age became more and more challenging in the last period because of all these but also because there are on the educational market a set of offers for a quick specialization. Thus, a few dozen hours, training pills, often taken from other cultures and not at all adapted to the one in which they are applied, come as alternatives to master programs that ask at least one year (60 credits) or even two years (180).

In these conditions, it is obviously difficult for candidates to enroll themselves and to be kept inside the university. If they finalize a university program, quite a lot graduates remain in fact uninterested in their genuine training, but still extremely sensitive to the type of diploma obtained and the possibility to work after.

If the same possibilities of professional insertion are offered by both a master degree and a several weeks training program, the balance became an unfair one. The candidates seem to be interested only on their future insertion within a job and not at all about their effective integration within the professional field.

It seems that the bureaucratic aspects of educational life became much more important than the essence of education and training itself.

For the remained "Don Quixote" scholars of educational system, especially in tertiary education, the emotional and motivated survival became a real challenge, in these conditions. It is a silent challenge, usually felt but not recognized, a challenge that has as a perverse effect the real decrease of their motivation for the qualitative work, or their migration towards other professional areas.

\section{The need for research, reflection and effective action}

The comments above presented are the result of a formally managed observation on several cohorts of graduate students in university, on teachers and other professional involved in in-service training. The observational process started in 2012. In that year, after two years of working far from the undergraduate and graduate students, a significant gap between previous generations and those I found out at my return blew up in my mind. My colleagues who continued their activity have equally noticed the decrease in the quality of the educational results in the new cohorts, but for somebody coming back after a while, the gap with all its qualitative implications appeared as being dramatic.

The spontaneous observation, initially, with the mentioned conclusive aspects have generated the idea of a more in depth scrutinizing of 
the situation, aiming not only to write down some conclusions but to find out appropriate solutions for solving, or at least improving a major issue.

There are some constraints that make almost impossible the radically change of the situation and they are intimately connected to the educational policy. But, still, some corrections can be done within the academic activity itself.

An intentioned and managed observation aiming to generate hypotheses and ideas to be analyzed and connected has been initiated. This was accompanied by the implementation of a complex assessment system for several successive cohorts. It is based on defined qualitative criteria, focused on elements of competencies (or even competencies as a whole), kept for all the involved cohorts, even if the topics of the assessment has been changed each year .

The declared attitude versus learning and some motivational aspects have been investigated by the means of questionnaires and focus groups during the activity of courses and seminars. Their results have been and are (the activity is in progress) analyzed in connections with the compared results of the students' assessment along several academic years when the assessment way has common and constant core milestones.

The methodology of teaching has been adapted year after year, according to the master program, the study year, and the concrete group personality of each cohort. A considerable number and facets and nuanced difficulties have been highlighted. The results of this on process research will be subject of further presentations.

This research is focused on the tertiary education, but it is really necessary a analysis of what is happening along the whole trajectory of schooling with the attitudes of students versus the learning process. Causes, factors of influence should be detected, analyzed and measures of decreasing their negative influence must be taken into account. Every activity field of a society (no matter how important they claim to be) receives human resources formed basically and as specialists, from the educational system. Scholars and teachers, managers in educational field and politicians must become aware about this truth. The entire society has to understand that without education society can exist no other than chaotic. Here, in educational field (family and school) are to be found the roots of the well being and well functioning of the society, and the causes of failures as well. Education must be a national and worldwide priority, but not only in the official documents. The Kingdom of to Pretend must be eradicated first in the area of education!

\section{References}

Bakar, K. A., Sulaiman, N. F. \& Rafaai, Z. A. M. (2010). Self-Determination Theory and Motivational Orientations of Arabic Learners: A Principal 
Component Analysis. GEMA Online ${ }^{\mathrm{TM}}$ Journal of Language Studies, 10/1, 71-86. Accessed on 24.09.2017 http://ejournal.ukm.my/gema/article/view/127

Chiew Fen Ng and Poh Kiat Ng . (2015). A Review of Intrinsic and Extrinsic Motivations of ESL Learners. International Journal of Languages, Literature and Linguistics, Vol. 1, No. 2, June 2015. Accessed in 24.09.2017 on: http://www.ijll1.org/vol1/20-L016.pdf

Deci, E. \& Ryan, R. (2000). The "What" and "Why" of Goal Pursuits:

Human Needs and the Self-Determination of Behaviour. Psychological Inquiry, 11, 227-268.

Murphy, P. K. \& Alexander, P. A. (2000).A motivated exploration of motivation terminology. Contemporary Educational Psychology, 25, 3-53

Oletić A., Ilić N.(2014). Intrinsic and Extrinsic Motivation for Learning English as a Foreign Language. ELTA Journal • December 2014 • Volume 2, No. 2. Accessed on 24.09.2017: http://eltajournal.org.rs/wpcontent/uploads/2014/12/V-Intrinsic-and-Extrinsic-Motivation-forLearning-English-as-a-Foreign-Language-by-Aleksandra-Oleti\%C4\%87and-Nina-Ili\%C4\%87.pdf

Principles of Adult Learning \& Instructional Systems Design Adult Learning. (W.Y). accessed on https://www.nhi.fhwa.dot.gov/downloads/freebies/172/pr\%20precourse\%20reading\%20assignment.pdf, 23.09.2017

Simon, J. R., Howard, J. H., \& Howard, D. V. (2010). Adult Age Differences in Learning from Positive and Negative Probabilistic Feedback. Neuropsychology, 24(4), 534-541. http://doi.org/10.1037/a0018652 on https://www.ncbi.nlm.nih.gov/pmc/articles/PMC2900815/

The learning process. (2003) on:

(http://www.dynamicflight.com/avcfibook/learning_process/) accessed on 23.09.2017

Türkkahraman M.(2012). The role of education in the societal development. Journal of educational and instructional studies in the world .November 2012, Volume: 2 Issue: 4; http://www.wjeis.org/FileUpload/ds217232/File/04.turkkahraman.pdf; accessed on 24.09.2017 